Western University

Scholarship@Western

2011

\title{
Lesion of cholinergic neurons in nucleus basalis enhances response to general anesthetics
}

Leung L. Stan

University of Western Ontario, sleung@uwo.ca

Follow this and additional works at: https://ir.lib.uwo.ca/physpharmpub

Part of the Medical Physiology Commons, and the Pharmacy and Pharmaceutical Sciences Commons

Citation of this paper:

L. Stan, Leung, "Lesion of cholinergic neurons in nucleus basalis enhances response to general anesthetics" (2011). Physiology and Pharmacology Publications. 72.

https://ir.lib.uwo.ca/physpharmpub/72 

Not for reproduction, distribution or commercial use.

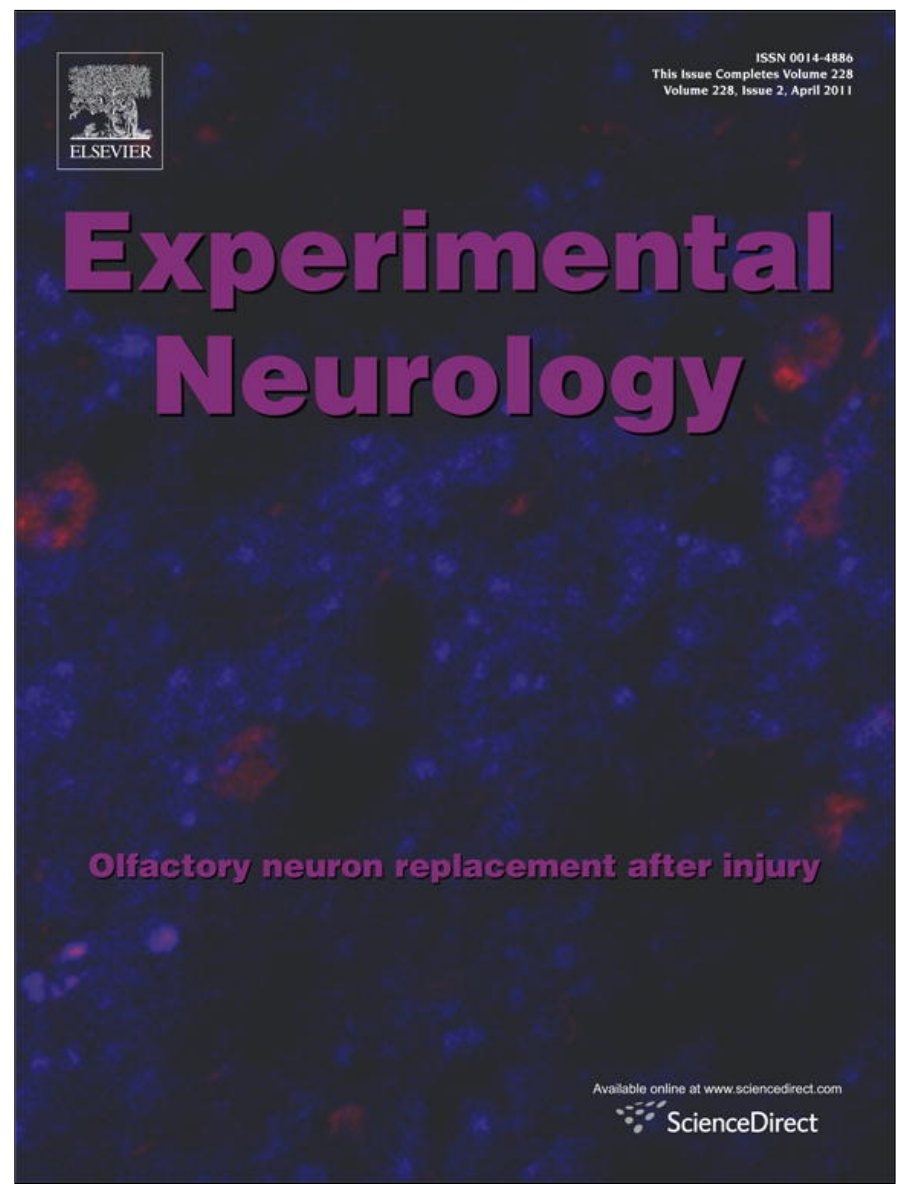

This article appeared in a journal published by Elsevier. The attached copy is furnished to the author for internal non-commercial research and education use, including for instruction at the authors institution and sharing with colleagues.

Other uses, including reproduction and distribution, or selling or licensing copies, or posting to personal, institutional or third party websites are prohibited.

In most cases authors are permitted to post their version of the article (e.g. in Word or Tex form) to their personal website or institutional repository. Authors requiring further information regarding Elsevier's archiving and manuscript policies are encouraged to visit:

http://www.elsevier.com/copyright 


\title{
Lesion of cholinergic neurons in nucleus basalis enhances response to general anesthetics
}

\author{
L. Stan Leung a,b,*, Sophie Petropoulos ${ }^{\text {a }}$, Bixia Shen ${ }^{\text {a }}$, Tao Luo ${ }^{\text {a }}$, Ian Herrick ${ }^{\mathrm{c}}$, N. Rajakumar ${ }^{\mathrm{d}, \mathrm{e}}$, Jingyi Ma ${ }^{\mathrm{a}}$ \\ ${ }^{a}$ Department of Physiology and Pharmacology, University of Western Ontario, London, Ontario, Canada N6A 5C1 \\ ${ }^{\mathrm{b}}$ Department of Clinical Neurological Sciences, University of Western Ontario, London, Ontario, Canada N6A 5C1 \\ ${ }^{c}$ Department of Anesthesia and Perioperative Medicine, University of Western Ontario, London, Ontario, Canada N6A 5C1 \\ d Department of Psychiatry, University of Western Ontario, London, Ontario, Canada N6A 5C1 \\ e Department of Anatomy and Cell Biology, University of Western Ontario, London, Ontario, Canada N6A 5C1
}

\section{A R T I C L E I N F O}

\section{Article history:}

Received 6 December 2010

Revised 16 January 2011

Accepted 24 January 2011

Available online 2 February 2011

\section{Keywords:}

Basal forebrain

Loss of righting reflex

Acetylcholine

Propofol

Pentobarbital

Halothane

Delirium

\begin{abstract}
A B S T R A C T
Acetylcholine in the brain has been associated with consciousness and general anesthesia effects. We tested the hypothesis that the integrity of the nucleus basalis magnocellularis (NBM) affects the response to general anesthetics. Cholinergic neurons in NBM were selectively lesioned by bilateral infusion of 192IgG-saporin in adult, male Long-Evans rats, and control rats were infused with saline. Depletion of choline-acetyltransferase (ChAT)-immunoreactive cells in the NBM and decrease in optical density of acetylcholinesterase (AChE) staining in the frontal and visual cortices confirmed a significant decrease in NBM cholinergic neurons in lesioned as compared to control rats. AChE staining in the hippocampus and ChAT-positive neurons in the medial septum-vertical limb of the diagonal band were not different between lesioned and control rats. When a general anesthetic was administered, lesioned compared to control rats showed significantly longer duration of loss of righting reflex (LORR) after propofol ( 5 or $10 \mathrm{mg} / \mathrm{kg}$ i.v.), pentobarbital (20 or $40 \mathrm{mg} / \mathrm{kg}$ i.p.) but not halothane $(2 \%)$. However, the behavioral excitation, as indicated by horizontal movements, induced by halothane was reduced in lesioned as compared to control rats. Reversible inactivation of NBM with GABA receptor agonist muscimol increased slow waves in the neocortex during awake immobility, and prolonged the duration of LORR and loss of tail-pinch response after propofol, pentobarbital and halothane. In summary, lesion of NBM cholinergic neurons or inactivation of the NBM prolonged the LORR response to general anesthetic drugs.
\end{abstract}

(C) 2011 Elsevier Inc. All rights reserved.

\section{Introduction}

Acetylcholine (Ach) in the brain has long been associated with consciousness (Perry et al., 1999). Ach release was found to increase during waking and rapid-eye movement sleep as compared to slowwave sleep (Vazquez and Baghdoyan, 2001; Phyllis, 2005). Cholinergic function is considered to be vital in attention, memory and other cognitive processing (Everitt and Robbins, 1997; Sarter et al., 2005). Cholinergic neuronal pathology, as found in Alzheimer's disease, is accompanied by cognitive and behavioral deficits (Whitehouse et al., 1981; Guela and Mesulam, 1994; Bartus, 2000; Auld et al., 2002).

Cholinergic inputs to the cerebral cortex originate from neurons in the basal forebrain, among which the nucleus basalis magnocellularis (NBM) projects to the neocortical mantle, and medial septumdiagonal band nuclei project to the hippocampus (Bigl et al., 1982; Mesulam et al., 1983; Mckinney et al., 1983; Saper, 1984; Wenk, 1997;

\footnotetext{
* Corresponding author at: Dept Physiology and Pharmacology, Medical Sciences Building, University of Western Ontario, London, ON, Canada N6A5C1. Fax: +1 1519661 3827.

E-mail address: sleung@uwo.ca (L.S. Leung).
}

Semba, 2000; Jones, 2004). The basal forebrain also contains GABAergic and glutamatergic neurons that project to the cortex (Gritti et al., 1997; Manns et al., 2003; Hassani et al., 2009). The basal forebrain (Wenk, 1997; Detari et al., 1999; Cape and Jones, 2000; Szymusiak et al., 2000; Lee et al., 2005), together with the thalamus (Steriade, 2000; Dringenberg and Olmstead, 2003), is important for cortical activation, manifested as a decrease in slow waves and an increase in high-frequency oscillations.

General anesthesia is a reversible state of unconsciousness, during which surgical operations may be performed, and the desirable components are loss of response to pain, general awareness, movement and memory without compromising vital functions (Franks, 2008). Despite advances made on the molecular action of various general anesthetics, such as their action on $\mathrm{K}^{+}$channels, $\mathrm{GABA}_{\mathrm{A}}$, nicotinic and glutamate receptors (Franks, 2008), brain structures underlying general anesthesia remain unclear. Anesthetic-induced loss of consciousness was enhanced if arousal related brain structures were ablated or inactivated (Devor and Zalkind, 2001; Nelson et al., 2002; Flint et al., 2010; Franks, 2008; Kelz et al., 2008; Lu et al., 2008; Luo and Leung, 2009), and sleep deprivation increased the potency of propofol and isoflurane (Tung et al., 2002). 
Relations between Ach and general anesthesia have emerged. An anticholinesterase that increased central Ach levels was shown to reduce the depth of anesthesia induced by propofol or isoflurane (Meuret et al., 2000; Hudetz et al., 2003). Pain et al. (2000) reported that central Ach depletion by intracerebroventricular (icv) administration of 192IgG-saporin reduced the sedative potency of low-dose ( $30 \mathrm{mg} / \mathrm{kg}$ i.p.) propofol, although a subsequent study (Laalou et al., 2008) reported that the same depletion increased the anesthesia potency of propofol ( $>100 \mathrm{mg} / \mathrm{kg}$ i.p.). Laalou et al (2008) concluded that the main effect was mediated by immunotoxin lesion in the medial septum/vertical diagonal band of Broca.

Consistent with the view that cholinergic neurons in the NBM contribute to the maintenance of waking, we hypothesize that lesion of NBM cholinergic neurons, or inactivation of the NBM, will enhance the behavioral effects of a general anesthetic. Specific lesion of cholinergic neurons in NBM was made by local infusion of 192IgGsaporin, and inactivation of the NBM was made by local infusion of muscimol, a $\mathrm{GABA}_{\mathrm{A}}$-receptor agonist. Three general anesthetics, halothane, pentobarbital and propofol were used, and the loss of righting reflex (LORR) and the loss of tail-pinch pain responses, together with neocortical EEG changes were measured. LORR in animals after a general anesthetic drug is considered to be a measure that corresponds to a loss of consciousness in humans (Franks, 2008).

\section{Methods}

Animals

Experiments were carried out on adult male Long Evans rats (250280 g; Charles River Canada). All animals were given water and regular rat chow ad libitum and housed under climate-controlled conditions with a $12 \mathrm{~h}$ light/dark cycle (lights on at 7:00 h). All procedures were approved by the local Animal Use Committee and conducted according to the guidelines of the Canadian Council for Animal Care.

\section{Lesion of NBM}

A rat was anesthetized with sodium pentobarbital $(60 \mathrm{mg} / \mathrm{kg}$ i.p.) and placed in a stereotaxic apparatus with bregma and lambda in a horizontal plane. NBM will refer to basal forebrain neurons that project to the neocortex. Cholinergic neurons in the NBM lesion was made by bilateral infusion of 192IgG-saporin $(0.15 \mu \mathrm{g} / 0.5 \mu \mathrm{l} /$ side or $0.5 \mu \mathrm{l}$ of $1.44 \mu \mathrm{M}$ solution in saline), via a 30 -gage cannula, into substantia innominata (SI) at posterior (P) $1.4 \mathrm{~mm}$ and lateral (L) $\pm 2.7 \mathrm{~mm}$ of bregma, and $7.8 \mathrm{~mm}$ ventral (V) from the skull surface (Fig. 1; Paxinos and Watson, 1998). Sham-lesion rats received bilateral saline infusion $(0.5 \mu \mathrm{l} /$ side $)$ into SI. The volume $(0.5 \mu \mathrm{l})$ used was identical (Berntson et al., 2002; Kaur et al., 2008), or similar (0.4-0.8 $\mu$ used by Heckers et al., 1994; Laalou et al., 2008), to that used in other intra-NBM lesion studies. Saline with or without 192IgG-saporin was delivered by an infusion pump (Harvard Apparatus, South Natick, MA) over 10 min, after which the cannula was kept in place for another $10 \mathrm{~min}$ to allow for diffusion before retraction. Recording electrodes were inserted bilaterally into the frontal cortex (FC; at anterior (A) 1.4, L2, V1.5, units in $\mathrm{mm}$ ), visual cortex (VC; P7, L3, V1.5), and hippocampus (bipolar electrodes at P3.8, L2.7, V3 and V2). Each electrode was a stainless steel wire of $125 \mu \mathrm{m}$ diameter insulated with Teflon except at the cut end. The electrodes in the FC and VC were targeted at layer V of the cortex, while the hippocampal electrodes were targeted to straddle the CA1 cell layer. Two screws placed over the cerebellum and frontal cortex served as reference and ground electrodes respectively. Each electrode was connected to an amphenol socket, which was then embedded with the skull screws in dental cement on top of the rat's skull.

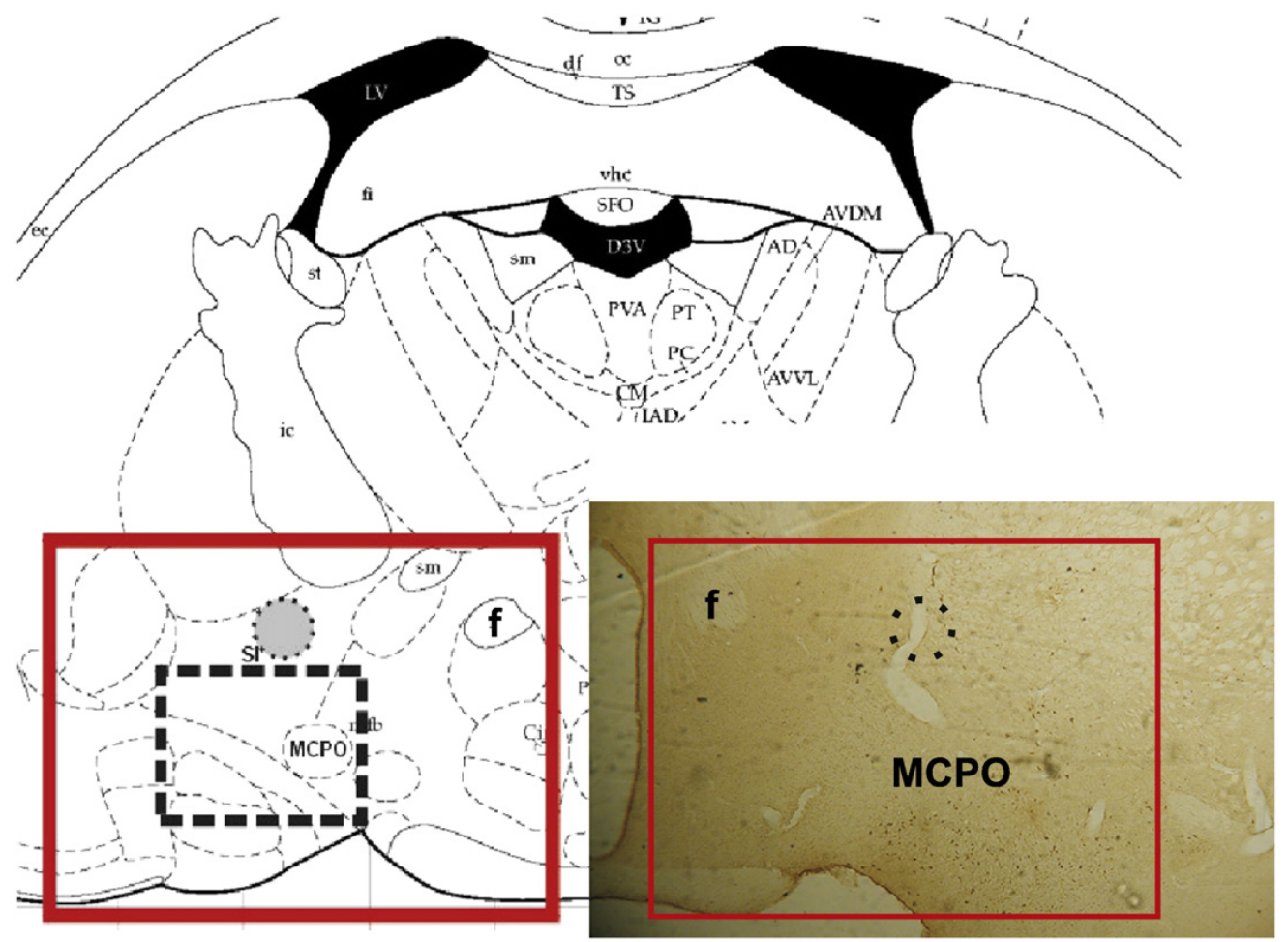

Fig. 1. Schematic diagram of coronal section $1.4 \mathrm{~mm}$ posterior to bregma (Paxinos and Watson, 1998) with superimposed choline acetyl transferase (ChAT) immunostained section (right side) from a control, sham-lesion rat. Left side shows intended target of cannula delivering 192IgG saporin bilaterally (gray dotted circle), large (solid line) rectangle delimits area for counting ChAT-immunopositive neurons, small (dashed line) rectangle for counting parvalbumin-immunopositive neurons. Right side shows putative cannula track in sham-lesion rat, and ChAT-immunopositive neurons in magnocellular preoptic area (MCPO). MCPO, SI (substantia innominata), and $\mathrm{f}$ (fornix) on the left side as labeled in Paxinos and Watson (1998); right side, corresponding structures in histological section. 
General anesthetic drug, EEG recording and behavioral tests

Response to anesthetics was tested in lesioned and control rats at 13-29 days after 192IgG-saporin/saline infusion. Three general anesthetics - halothane, sodium pentobarbital and propofol - were used, following procedures used in previous studies (Ma et al., 2002; Ma and Leung, 2006; Long et al., 2009). Halothane (2\%) in pure oxygen was delivered by a calibrated vaporizer, at $8 \mathrm{l} / \mathrm{min}$, into a Plexiglas observation chamber $(30 \times 30 \times 30 \mathrm{~cm})$, and leaked through small holes at the top. Sodium pentobarbital was injected at 20 or $40 \mathrm{mg} / \mathrm{kg}$ i.p. and propofol at 5 or $10 \mathrm{mg} / \mathrm{kg}$ i.v.; the lower dose of each anesthetic drug was below, and the higher dose was above, the typical LORR in normal rats. The i.p. route of pentobarbital injection is widely used for rodents. Intravenous propofol is the normal route used in humans, and in Long-Evans rats, surgical anesthesia induced by propofol required 15-20 times less dose i.v. than i.p. Two days before propofol administration, the rat was given pentobarbital anesthesia, and an intravenous catheter was placed into a femoral vein, threaded under the body skin, and exteriorized above the skull. All rats were given three anesthetics, with propofol administered as the last anesthetic, while about equal number of rats received halothane or pentobarbital first; repeated administration of anesthetic drugs in one rat was separated by at least two days. Control and lesion rats followed the same sequence of anesthetic administration. For a particular dose of an anesthetic, more than half the rats were done with the experimenter unaware of the treatment of the rat, and statistical significance reported in the Results below remained when only blinded experiments were included.

EEGs from one FC, one VC, and hippocampal electrodes were recorded on a polygraph, and digitized and stored on a microcomputer. Recordings were made during quiet-awake before an anesthetic drug, and at various times after an anesthetic, in particular at a time showing maximal effect of the drug (i.e., LORR), which was $10 \mathrm{~min}$ after pentobarbital i.p. and $3 \mathrm{~min}$ after propofol i.v. EEG recordings were not made after halothane anesthesia in the present study. All rats retained spontaneous respiration after a general anesthetic.

As a measurement of the delirium, also known as stage II anesthesia, induced by a volatile anesthetic (Guedel, 1951), horizontal movements (locomotion) were quantified by measuring the number of infrared beam interruptions after administration of halothane (Ma et al., 2002; Long et al., 2009). Each lesioned or control rat was habituated for $25 \mathrm{~min}$ in the chamber before the delivery of halothane (2\%). The number of infrared beam interruptions was stored for the period of 5 min prior to, and 10 min after halothane administration.

Behavioral tests after a general anesthetic consisted of pain and righting responses. The same experimenter was involved in the behavioral tests of a given anesthetic. Pain response to tail pinch was tested. A positive pain response was considered to be a movement of the body or more than one limb in response to the pinch by an alligator clip on the tail. The pinch was applied periodically to the middle part of the tail but not to the same part successively. A tail pinch induced a normal rat to move but caused no permanent tissue damage. The righting reflex was considered normal when the rat could right itself from a supine position. After exposure to halothane in the observation chamber for $10 \mathrm{~min}$, pain and righting responses were tested in room air. Tests were made starting $5 \mathrm{~min}$ after pentobarbital (i.p.) injection and immediately after propofol (i.v.) injection. Rats that did not lose their righting were not tested for pain response, since they were shown always to retain positive pain responses (with a minimal pinch to the tail).

\section{Inactivation of NBM}

A separate group of 16 rats was studied after muscimol inactivation of the NBM. These rats were implanted with hippocampal and frontal cortical electrodes, as above. In addition, guide cannulae (23-gage) were implanted bilaterally over NBM (P1.4, $\mathrm{L} \pm 2.7)$. At least 7 days after surgery, experiments were performed in rats that were habituated to the laboratory environment. A 30-gage cannula was lowered into the guide cannula to the depth of the NBM (V7.8), and muscimol $(0.4 \mu \mathrm{g}$ in $0.4 \mu \mathrm{l}$ saline, $9.8 \mathrm{mM})$ or $0.4 \mu \mathrm{l}$ of saline was infused bilaterally. Infusion was made manually by a Hamilton syringe at a rate of $\sim 0.5 \mu \mathrm{l} / \mathrm{min}$, and EEG recordings (below) were made before and after infusion. Administration of a general anesthetic drug was made 10 min after muscimol or saline infusion in the NBM. Halothaneinduced movements were studied by measuring infrared beam interruptions in a chamber following muscimol/saline infusion into the NBM (at 10 min before onset of halothane administration), for $4 \mathrm{~min}$ before and $10 \mathrm{~min}$ after halothane delivery.

\section{Histological and immunocytochemical staining}

At the end of experiments, saporin and sham lesioned rats were given a surgical anesthetic dose of pentobarbital and perfused through the heart with $100 \mathrm{ml}$ of $0.9 \%$ saline followed by $500 \mathrm{ml}$ of $4 \%$ paraformaldehyde solution (Sigma) in $0.1 \mathrm{M}$ phosphate buffer (PB; $\mathrm{pH}$ 7.4). The rat brain was removed and postfixed with $18 \%$ sucrose in phosphate-buffered saline for $24 \mathrm{~h}$ at $4{ }^{\circ} \mathrm{C}$. Coronal brain sections of $40-\mu \mathrm{m}$ thick were cut by a freezing microtome. Electrode and cannula locations were verified from thionin-stained sections. The degree of preservation of cholinergic fibers in the neocortex and hippocampus was assessed by acetylcholinesterase (AChE) histochemistry (Leung, 1987). AChE staining protocol was modified from the Koelle copper thiocholine method (Koelle and Friedenwald, 1949), using acetylthiocholine iodide as a false substrate to tag the AChE enzyme and ethopropazine as an inhibitor of non-specific cholinesterases Digital photographs were taken using the same parameters (microscope lighting, digital camera aperture and shutter speed settings) at FC $(\sim \mathrm{A} 2), \mathrm{VC}(\sim \mathrm{P7} .3)$, parietal cortex $(\sim \mathrm{P} 3)$ and dorsal hippocampus $(\sim \mathrm{P3})$. A computer software program (ImageJ, National Institutes of Health, U.S.A.) was used to quantify AChE staining by means of an average optical density (OD) measure on one side. The OD average was taken from a rectangular window. For the FC and VC, the window was $1.5-2 \mathrm{~mm}$ wide (medial edge at $\sim \mathrm{L} 1.5-2$ ), and included layers I to $\mathrm{V}$; for the hippocampus, it was $1-1.5 \mathrm{~mm}$ wide and included layers from the alveus to stratum lacunosum-moleculare of hippocampal CA1.

Choline acetyltransferase (ChAT) and parvalbumin (PARV) immunocytochemistry, using procedures described before (Ma et al., 2004), were performed on coronal sections through the basal forebrain. Briefly, the sections were rinsed in $\mathrm{PB}$ and incubated at $4{ }^{\circ} \mathrm{C}$ for $48 \mathrm{~h}$ in primary antibody solution containing mouse monoclonal ChAT (1:200; Biogenesis) or mouse monoclonal PARV (1:2000; Sigma) in $1 \%$ normal goat serum. Sections were washed in three changes of PB and followed by biotin-conjugated goat anti-mouse secondary antiserum (1:200; BioCan) for $1 \mathrm{~h}$ in room temperature. After rinsing several times in $\mathrm{PB}$, the sections were incubated in an $\mathrm{ABC}$ complex solution (Vector Laboratories) for $1 \mathrm{~h}$ at room temperature, and enhanced in a solution containing $0.05 \%$ diaminobenzidine tetrahydrochloride (DAB, Sigma) and $0.003 \%$ hydrogen peroxide in PB at room temperature. Digital pictures were made at $40 \times$ and $100 \times$ magnification of coronal brain sections through NBM and medial septum. ChAT immunopositive (cholinergic) neuronal cell bodies in the horizontal limb of the diagonal band (HDB)/magnocellular preoptic area (MCPO)/SI area of each side ( P1.4 and $\sim$ P0.8 of Paxinos and Watson, 2009) were counted on left and right sides in a $4 \mathrm{~mm}$ wide $\times 3 \mathrm{~mm}$ high window (starting at L0.5; Fig. 1 ); neurons clearly within caudate-putamen were not counted. Medial septum and vertical limb of the diagonal band neurons (ChAT or PARV) were counted bilaterally in a section at $\sim$ A0.5. PARV immunopositive neurons were counted in a $1.6 \mathrm{~mm} \times 1.2 \mathrm{~mm}$ window that included the HDB/MCPO just lateral to the optic tract ( P1.4; Fig. 1), excluding 
neurons in the caudate-putamen. The persons doing the cell counting were blind to the treatment of the rats. Selected sections recounted by the same or a different person showed high reproducibility.

\section{Data analysis}

Artifact free EEG, digitized at $200 \mathrm{~Hz}$, was selected for power spectral analysis (Leung, 1985). Each EEG segment consisted of 1024 points $(5.12 \mathrm{~s})$, and 6-12 segments were used for each power spectrum consisting of $>60$ degrees of freedom after smoothing across frequency bins (frequency resolution $0.19 \mathrm{~Hz}$, independent bins every $0.78 \mathrm{~Hz}$ ). Records with prolonged high-voltage spindle activity $(6-11 \mathrm{~Hz})$ in the neocortex during quiet-awake were not included for power spectral analysis. The average integrated power of the EEG was determined at different frequency ranges by averaging the power across frequency bins within the range of delta $(0.8-4 \mathrm{~Hz})$, theta $(4-10 \mathrm{~Hz})$, beta $(13-32 \mathrm{~Hz})$, low gamma $(32-58 \mathrm{~Hz})$ and high gamma $(62-100 \mathrm{~Hz})$. Power was determined in logarithmic units, and $4.8 \mathrm{log}$ units of power were equivalent to a $0.5 \mathrm{mV}$ peak-to-peak sine wave.

Wilcoxon signed-rank test was used for statistical testing. Parametric statistics were not applied to samples showing no variance (e.g., zero LORR duration in the whole group), or inhomogeneous variance (movement data). Pearson correlation coefficients were calculated between pairs of histological and behavioral measures. Group data are presented as mean \pm standard error of the mean (SEM). Differences were considered significant if $\mathrm{P}<0.05$.

\section{Results}

Cholinergic markers were decreased in 192IgG-saporin lesion of the NBM

In the group of lesioned rats infused with 192IgG-saporin $(n=9)$, a decrease in AChE stain intensity was found in the lateral neocortex, as compared to the control, sham-lesioned rats infused with saline $(n=6$; Figs. $2 A$ and $\mathrm{D}$ ). This was confirmed by optical density measurements in frontal, parietal and visual cortices (Table 1). On the other hand, the AChE staining of the dorsal hippocampus in the saporin-lesioned rats was not statistically different from that of control, sham-lesioned rats (Figs. 2A and D; Table 1). The number of ChAT immunoreactive neurons in the HDB/MCPO/SI (at P1.4) was significantly decreased in lesioned as compared to control rats (Figs. $2 \mathrm{C}$ and F; Table 2). As a group, the average number of ChAT-immunoreactive neurons in saporin-lesioned rats was estimated to be $38 \%$ of that in sham-lesioned rats at P1.4 (Table 2, 6 sham-lesion and 9 saporin-lesion rats), and 55\% of that in sham-lesioned rats at P0.8 ( 5 sham-lesion and 8 saporin-lesion rats). The number of ChAT immunoreactive neurons in NBM (total counted in both P0.8 and P1.4 sections) was significantly correlated with the average AChE staining intensity in the FC (correlation coefficient $\mathrm{r}=0.72, \mathrm{P}<0.01, \mathrm{n}=13$ rats). By contrast, the number of ChAT immunoreactive neurons in the medial septal/vertical limb of the diagonal band area was not different between control and lesioned rats (Figs. 2B and E; Table 2). In addition, there was no difference in the number of PARV immunoreactive neurons in the horizontal limb of the diagonal band at $\sim$ P1.4 between control and lesioned rats (Table 2).

\section{Propofol's anesthetic effects were prolonged in lesioned rats}

In both lesion and control rats, the EEG at the electrodes at the FC and VC showed low-voltage fast activity during awake-immobility, as compared to high-voltage, slow wave activity during slow wave sleep (data not shown). High-voltage spindle activity $(6-11 \mathrm{~Hz})$ during awake-immobility showed similar incidence in control and lesion rats, and slow EEG power (delta activity) excluding periods of highvoltage spindle activity did not differ between control and lesioned rats. Lesioned rats did not show any signs of sedation; they were responsive to touch, sound, and light like control rats and were capable of righting themselves. Differences between lesioned and control rats emerged only after administration of a general anesthetic drug.

Propofol $(5 \mathrm{mg} / \mathrm{kg}$ i.v.) induced a brief period of LORR in most control rats, but 2 of 6 rats retained righting; the duration of LORR averaged $2.5 \pm 1.2 \mathrm{~min}(n=6$, including the 2 rats that retained righting). In contrast, all lesioned rats showed a LORR immediately after $5 \mathrm{mg} / \mathrm{kg}$ i.v. propofol, and the duration of LORR was 11.8 \pm 0.9 min $(n=9)$, significantly longer than that in control rats $(\mathrm{P}<0.005$, Wilcoxon; Fig. 3A). Only 2 of 6 control rats lost tail-pinch pain response after propofol, and the average duration of lost pain response was $1 \pm 0.6 \min (n=6)$ for control rats. However, all lesioned rats showed a loss of tail pinch response after propofol, with the duration of loss averaging $5.9 \pm 0.8 \mathrm{~min}(n=9)$, significantly longer than that in control rats $(\mathrm{P}<0.005$, Wilcoxon). When given $10 \mathrm{mg} / \mathrm{kg}$ i.v. propofol, lesioned rats also showed a significantly longer duration of LORR as compared to control rats (Fig. 3B).

At $3 \mathrm{~min}$ after $5 \mathrm{mg} / \mathrm{kg}$ i.v. propofol, the EEG at the $\mathrm{FC}$ and $\mathrm{VC}$ showed increased slow waves, compared to baseline immobility, in association with the LORR in the lesioned rats (Fig. 4B1 and B2), and confirmed by power spectral analysis ( ${ }^{*}$ in Fig. 4B3). By contrast, the EEG in the control rats treated with propofol was mainly unchanged (Fig. 4A), except for a small but significant increase in gamma of 50$100 \mathrm{~Hz}$ (arrow in Fig. 4A3). When lesioned and control groups of rats were compared for power at the FC electrode, the post-propofol increase in integrated delta $(0.8-4 \mathrm{~Hz})$ EEG power was significantly larger in lesioned rats than control rats $(P<0.02$, Wilcoxon; Table 3$)$, while the increase in high-frequency gamma $(62-100 \mathrm{~Hz})$ power was significantly larger in control than lesioned rats $(\mathrm{P}<0.02$, Wilcoxon; Table 3). A similar trend was observed at the VC electrode, but the difference in delta or gamma power in VC after propofol was not statistically significant between lesioned and control rats (Table 3).

\section{Pentobarbital induced more prolonged loss of righting in lesioned rats}

Sodium pentobarbital ( $20 \mathrm{mg} / \mathrm{kg}$ i.p.) induced LORR averaging $32.5 \pm 4.5 \mathrm{~min}$ in control rats $(n=6)$, as compared to $64.3 \pm 7 \mathrm{~min}$ $(n=9)$ in lesioned rats $(P<0.005$, Wilcoxon; Fig. $3 C)$. The duration of loss of tail pinch responses was not different between control and lesioned groups (Fig. 3C). Pentobarbital (20 mg/ $\mathrm{kg}$ i.p.) induced a significant increase in delta activity and a decrease in $62-100 \mathrm{~Hz}$ gamma power, at both FC and VC electrodes, in both control and lesioned rats (data not shown). A higher dose of sodium pentobarbital ( $40 \mathrm{mg} / \mathrm{kg}$ i.p.) induced a longer duration of LORR and loss of tailpinch response in lesioned rats as compared to control rats (both $\mathrm{P}<0.05$, Wilcoxon; Fig. 3D).

Halothane induced less locomotion but no change in LORR duration in NBM lesioned rats

In order to test the behavioral excitation induced by halothane, horizontal movements were measured before and after $2 \%$ halothane delivery. During the baseline before halothane, the infrared beam interruptions were few (Fig. 3F) and not significantly different between lesioned and control rats ( 5 min of baseline, $\mathrm{P}>0.6$, Wilcoxon). When $2 \%$ halothane was administered to habituated control rats, they sniffed, made head movements, and moved around the observation chamber vigorously, even when they were ataxic. By contrast, some lesioned rats did not move after halothane administration. Rats stopped making voluntary movements 5-8 min after $2 \%$ halothane, and the time of movement cessation was not statistically different between control and lesioned rats. However, movements during halothane, as indicated by the number of infrared beam interruptions, were significantly decreased in lesioned rats, as compared to control rats (total interruptions for first 4 min during halothane, $\mathrm{P}<0.01$, Wilcoxon). 

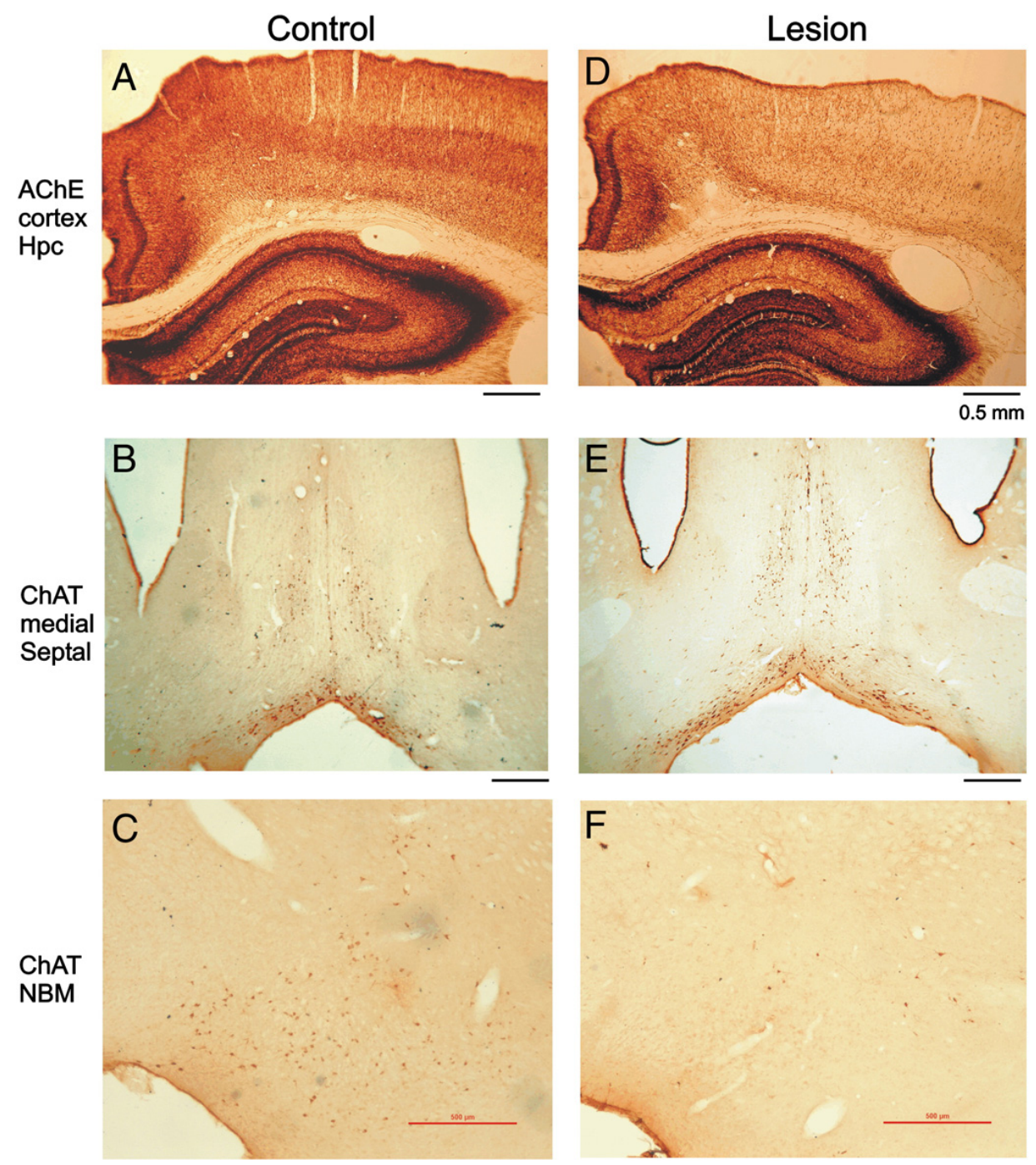

Fig. 2. Representative histological sections of sham-lesion control (left column, A-C) and 192IgG saporin-lesion rat (right column, D-F). As compared to the control rat (A), acetylcholinesterase (AChE) stain in the lateral neocortex, but not in the hippocampus, was strongly reduced in the lesion rat (D). Choline acetyl transferase (ChAT) immunoreactive neurons in the medial septum-vertical limb of the diagonal band area were similar in numbers in control (B) and lesion (E) rats. ChAT-immunoreactive neurons in the horizontal limb of the diagonal band/magnocellular preoptic area (nucleus basalis magnocellularis at $\sim \mathrm{P} 1.4$ ) were greatly reduced in the lesion rat (F) as compared to the control rat (C).

After 10 min of exposure to $2 \%$ halothane, rats were removed from the chamber into room air, and periodically tested for responses to tail pinch and righting, until each response recovered. There were no significant differences between lesioned and control rats in the duration of lost tail-pinch or righting response (Fig. 3E; P>0.05, Wilcoxon).

\section{Table 1}

Optical density (OD) of acetylcholinesterase (AChE) staining in the frontal, parietal and visual cortex, and dorsal hippocampus (CA1 area) of control sham-lesion and saporinlesion rats. A dark AChE stain has been converted to a high $\mathrm{OD}$ value, with zero = pale and $255=$ dark. OD values were averaged across left and right sides of one section per rat, and mean and standard error of the mean of the group are shown. ${ }^{* *} \mathrm{P}<0.01$, ${ }^{*} \mathrm{P}<0.05$, Wilcoxon, difference between lesion and control rats; NS, difference not statistically significant.

\begin{tabular}{lllll}
\hline & $\begin{array}{l}\text { Frontal } \\
\text { cortex }\end{array}$ & $\begin{array}{l}\text { Visual } \\
\text { cortex }\end{array}$ & $\begin{array}{l}\text { Parietal } \\
\text { cortex }\end{array}$ & Hippocampus \\
\hline $\begin{array}{l}\text { Control sham lesion } \\
(\mathrm{n}=6)\end{array}$ & $170.5 \pm 7.8$ & $154.1 \pm 5.1$ & $150.3 \pm 9.0$ & $157.9 \pm 4.9$ \\
Saporin lesion $(\mathrm{n}=9)$ & $117.3 \pm 4.0^{* *}$ & $126.8 \pm 2.6^{* *}$ & $131.0 \pm 8.1^{*}$ & $152.6 \pm 6.1^{\mathrm{NS}}$ \\
\hline
\end{tabular}

Correlation between histological and behavioral measures

Pearson correlation coefficients were calculated between AChE intensity in FC (averaged across both sides) to other histological and behavioral measures (Table 4). When all (6 control and 9 lesioned) rats were included, AChE intensity in FC was negatively correlated

Table 2

Neuronal counts of putative cholinergic and GABAergic neurons in the basal forebrain. Putative cholinergic neurons were immunoreactive to choline acetyltransferase (ChAT) and putative GABAergic neurons were immunoreactive to parvalbumin (PARV). Immunopositive neurons in the nucleus basalis magnocellularis (NBM) were counted bilaterally in the magnocellular preoptic area/horizontal limb of the diagonal band/ substantia innominata areas at $\sim$ P1.3, without including neurons within the caudateputamen (see Methods for details). ChAT neurons in the medial septum/diagonal band of Broca (MS/DBB) were counted bilaterally at $\sim \mathrm{A} 0.5 ; \mathrm{n}=$ number of rats. ${ }^{* *} \mathrm{P}<0.002$, Wilcoxon, difference between control and lesion rats; NS, not statistically significant.

\begin{tabular}{ccll}
\hline & $\begin{array}{l}\text { ChAT neurons } \\
\text { in NBM }\end{array}$ & $\begin{array}{l}\text { PARV neurons } \\
\text { in NBM }\end{array}$ & $\begin{array}{l}\text { ChAT neurons } \\
\text { in MS/DBB }\end{array}$ \\
\hline $\begin{array}{c}\text { Control sham } \\
\text { 192 IgG-Saporin } \\
\text { lesion in NBM }\end{array}$ & $\begin{array}{c}173 \pm 14(\mathrm{n}=6) \\
665^{* *}(\mathrm{n}=9)\end{array}$ & $\begin{array}{l}130 \pm 19(\mathrm{n}=5) \\
139 \pm 11(\mathrm{n}=9)^{\mathrm{NS}}\end{array}$ & $\begin{array}{l}278 \pm 25(\mathrm{n}=6) \\
279 \pm 19(\mathrm{n}=9)^{\mathrm{NS}}\end{array}$ \\
\hline
\end{tabular}




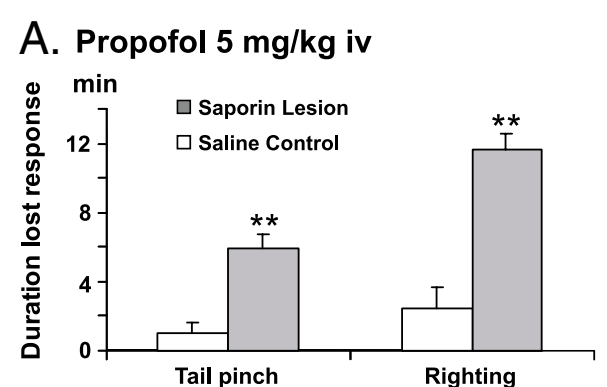

C. Pentobarbital 20mg/kg ip

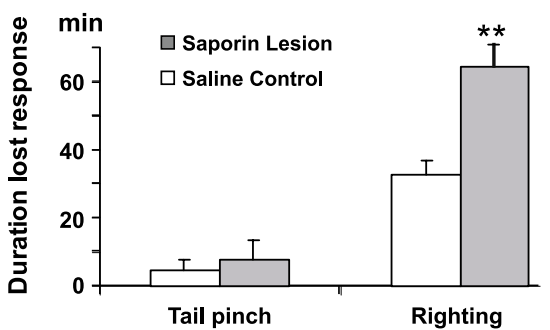

E. Halothane (2\%)

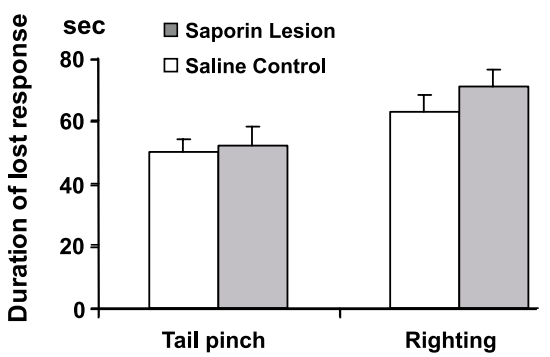

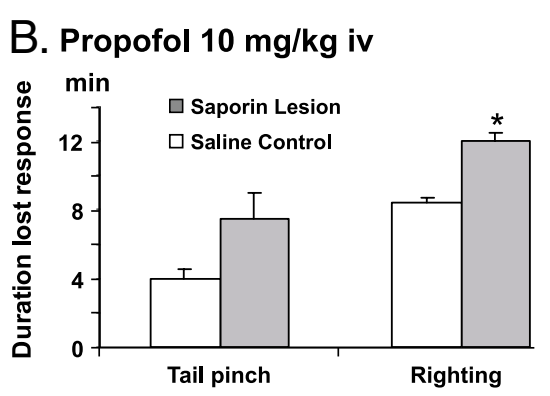

D. Pentobarbital 40mg/kg ip

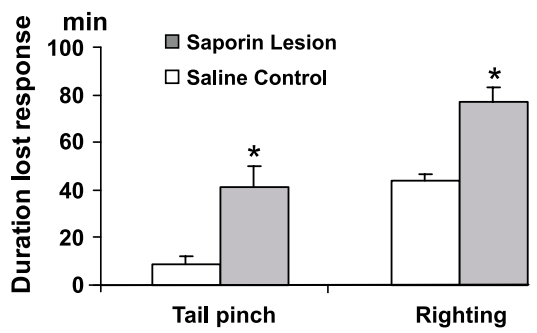

F. Halothane (2\%)

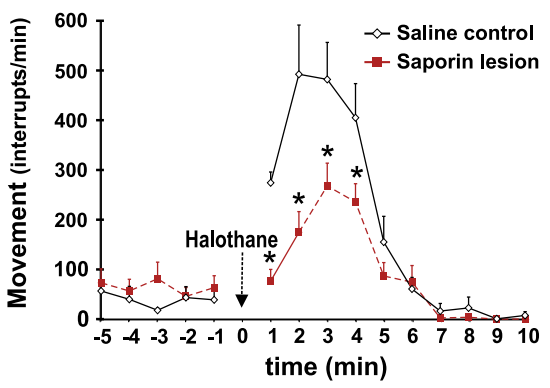

Fig. 3. Cholinotoxin (192IgG-saporin) lesion as compared to control (sham) lesion of the nucleus basalis magnocellularis enhanced response to propofol (5-10 mg/kg i.v.) and pentobarbital (20-40 mg/kg, i.p.) but not to halothane (2\%). Lesion rats, as compared to control rats, showed a significant increase in duration of loss of righting reflex after propofol (A, B) and pentobarbital (C, D), and an increase in the duration of loss of tail-pinch response to $5 \mathrm{mg} / \mathrm{kg}$ i.v. propofol (A) and $40 \mathrm{mg} / \mathrm{kg}$ i.p. pentobarbital (D). ${ }^{* *} \mathrm{P}<0.01$, ${ }^{*} \mathrm{P}<0.05$, Wilcoxon test. E. No differences in tail-pinch and righting responses were seen between lesion and control rats during emergence from $2 \%$ halothane. (F) The number of horizontal movements induced by halothane ( $2 \%)$ was smaller in lesion as compared to control rats $\left({ }^{*} \mathrm{P}<0.05\right.$, Wilcoxon test for fist 4 min after halothane). Horizontal movements were detected by interruptions of infrared beams, for $5 \mathrm{~min}$ before and $10 \mathrm{~min}$ after $2 \%$ halothane administration. All experiments used six control rats and 9 lesion rats, except 4 control and 4 lesion rats in experiments shown in parts B and D. All values are mean \pm SEM.

with, after Bonferroni adjustment for multiple comparisons, the duration of loss of pain after propofol $(\mathrm{P}<0.05)$ and the duration of LORR after propofol $(\mathrm{P}<0.01)$.

\section{Muscimol infusion in the NBM}

In order to extend the validity of cholinergic lesion of the NBM, a reversible lesion was made by infusion of muscimol into the NBM and compared with infusion of saline into the NBM of the same rat. No significant change in neocortical EEG was detected when $0.4 \mu \mathrm{l}$ saline was infused bilaterally into the NBM (data not shown). However, less than $5 \mathrm{~min}$ after bilateral infusion of muscimol $(0.4 \mu \mathrm{g}$ in $0.4 \mu \mathrm{l}$ saline per side) into the NBM, slow EEG waves appeared at FC and VC electrodes during awake immobility (Fig. 5). Spectral analysis revealed that the slow EEG was mainly within the delta frequency band (Fig. 5B), and the integrated delta power during awake immobility was significantly $(\mathrm{P}<0.05$, Wilcoxon) increased after muscimol, as compared to baseline, by $1.15 \pm 0.16(n=6)$ and $0.65 \pm 0.18(n=6)$ logarithmic units at the FC and VC electrode respectively. Gamma band $(30-100 \mathrm{~Hz})$ power during IMM was not significantly changed after muscimol infusion (Fig. 5B). Despite the presence of slow waves during IMM, the rat was not behaviorally asleep and it maintained intact righting and pain responses. The slow EEG after muscimol was desynchronized when spontaneous movements occurred (data not shown).

Propofol ( $5 \mathrm{mg} / \mathrm{kg}$ i.v.) was injected $10 \mathrm{~min}$ after bilateral infusion of saline or muscimol in the NBM. Propofol administration resulted in a significantly longer duration of LORR $(P<0.05$, Wilcoxon) when given after muscimol-NBM infusion ( $26.5 \pm 11.3 \mathrm{~min}, \mathrm{n}=10)$, as compared to the same rats after saline-NBM infusion $(2.7 \pm 1.0 \mathrm{~min}, \mathrm{n}=10$; Fig. 6A). Similarly, propofol induced a longer duration $(P<0.05$, Wilcoxon) of loss of tail-pinch response in the muscimol-infused group ( $3.2 \pm 0.8 \min n=10$ ), as compared to the saline-infused group $(0.2 \pm 0.2 \mathrm{~min}, \mathrm{n}=10$; Fig. $6 \mathrm{~A})$. Neocortical delta EEG was further increased by propofol after NBM muscimol-infusion (Fig. 5C), but the propofol-induced increase was small in muscimol- as compared to saline-infused rats (data of saline-infused rat not shown, but was similar to control rat in Fig. 4A).

NBM inactivation by muscimol also resulted in a prolongation of the anesthesia responses induced by sodium pentobarbital ( $20 \mathrm{mg} / \mathrm{kg}$ i.p.). 
A. Control
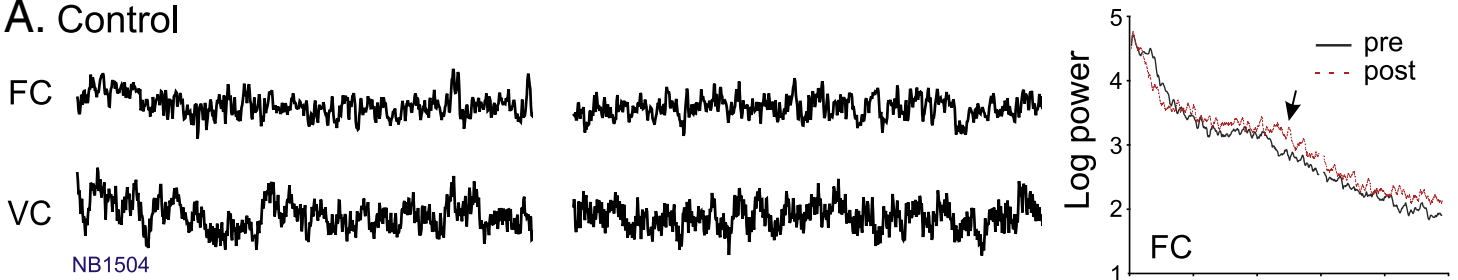

B. Lesion
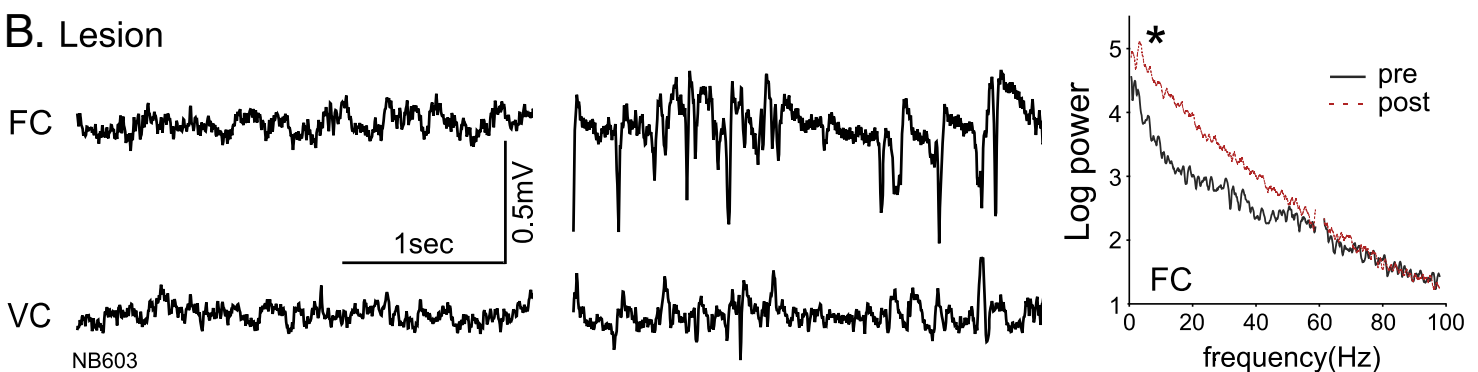

Fig. 4. EEG traces and power spectra of representative control and 192IgG-saporin lesion rats before and after propofol (5 mg/kg i.v.). Both control (A) and lesioned rat (B) showed desynchronized EEG in the frontal cortex (FC) and visual cortex (VC) before propofol (column 1). The control rat showed no loss of pain and righting responses, and minimal changes in the EEG, after propofol. In contrast, propofol resulted in a loss of pain and righting response in the lesioned rat, accompanied by an increase in slow EEG waves (column 2). Postpropofol EEG power spectra in FC (column 3) showed a slight increase in gamma power (arrow) in the control rat, and a large increase in slow EEG power $\left({ }^{*}\right)$ in the lesion rat, as compared to pre-propofol (baseline); $60-\mathrm{Hz}$ artifacts were removed in power spectra.

In rats given saline infusion into the NBM, pentobarbital sedated the animals, but with little LORR and no loss of tail-pinch response. In rats given $0.4 \mu \mathrm{g}$ muscimol bilaterally in the NBM, pentobarbital induced a duration of LORR of $55.1 \pm 16.8 \mathrm{~min}(\mathrm{n}=6)$ and a duration of loss of tailpinch response of $9.4 \pm 8.1 \mathrm{~min}(\mathrm{n}=6)$, significantly different from the respective duration after saline-NBM infusion $(\mathrm{P}<0.05$, respectively, Wilcoxon; Fig. 6B).

Horizontal movements induced by $2 \%$ halothane, as assessed by infrared beam interruptions, were recorded in 6 rats after saline or muscimol infusion into the NBM. During the 4 min before halothane, muscimol-infused rats showed a smaller number of movements than saline-infused rats $(P<0.05$, paired Wilcoxon, total beam interruptions during baseline; Fig. 6D). The increase in beam interruptions induced by halothane in the first $4 \mathrm{~min}$, above the 4-min baseline, was significantly smaller in muscimol-infused as compared to salineinfused rats $(\mathrm{P}<0.03$, paired Wilcoxon). All saline-infused rats increased movements after halothane, but some muscimol-infused rats did not move after halothane administration.

A more prolonged anesthesia response to $2 \%$ halothane was found after muscimol- as compared to saline-infusion in the NBM. Salineinfused rats showed durations of loss of righting and tail-pinch response (in room air after $10 \mathrm{~min}$ in $2 \%$ halothane) of $134.3 \pm 81.4$ and $32.5 \pm 7.2 \mathrm{~s}$, respectively (both $\mathrm{n}=6$; Fig. 6C). Muscimol-infused rats had durations of loss of righting and tail-pinch following halothane of $1258 \pm 199$ and $190 \pm 50$ s, respectively (both $n=6$;
Fig. 6C), significantly longer than the respective measure after salineinfusion ( $\mathrm{P}<0.05$, respectively; Fig. $6 \mathrm{C})$.

\section{Discussion}

We showed that a localized loss of the NBM cholinergic neurons, sparing the septohippocampal cholinergic neurons, prolonged LORR induced by propofol and pentobarbital, and reduced the behavioral excitation during $2 \%$ halothane. Muscimol infusion into the NBM greatly prolonged the duration of loss of righting and tail-pinch response after propofol, pentobarbital and halothane.

Infusion of $0.15 \mu \mathrm{g}$ 192IgG-saporin in the NBM resulted in an estimated loss of $45-62 \%$ of ChAT-immunopositive (cholinergic) neurons in the NBM, within $0.6 \mathrm{~mm}$ from the infusion site. This compares well with a $69 \%$ loss of cholinergic neurons after infusion of $0.26 \mu \mathrm{g}$ 192IgG-saporin in the NBM (Kaur et al., 2008). No significant change in the number of PARV-immunopositive neurons in the NBM was found in the present study, confirming the selectivity of 192IgGsaporin on cholinergic neurons (Heckers et al., 1994; Wenk et al., 1994; Kaur et al., 2008).

\section{Acetylcholine and neocortical activation}

In this study, no difference in slow EEG during awake-immobility was found between 192IgG-saporin lesion rats and control rats, as has

Table 3

Changes in EEG logarithmic power 3-5 min after propofol ( $5 \mathrm{mg} / \mathrm{kg}$ i.v.) for different frequency bands of delta $(\delta)$, low gamma $\gamma(30-58 \mathrm{~Hz})$ and high gamma $\gamma(62-100 \mathrm{~Hz})$ at the frontal and visual cortex electrodes of control, sham-lesion rats and rats with 192IgG-saporin lesion in the nucleus basalis magnocellularis. ${ }^{\#} \mathrm{P}<0.05$, significant change in power before and after drug for a particular group; ${ }^{*} \mathrm{P}<0.05$, significant difference in power change between lesion and control groups.

\begin{tabular}{|c|c|c|c|c|c|c|}
\hline \multicolumn{7}{|c|}{ Propofol (5 mg/kg i.v.) } \\
\hline & \multicolumn{3}{|c|}{ Sham control $(n=6)$} & \multicolumn{3}{|c|}{ Saporin-lesion $(\mathrm{n}=9)$} \\
\hline & $\delta$ change & Low $\gamma$ change & High $\gamma$ change & $\delta$ change & Low $\gamma$ change & High $\gamma$ change \\
\hline Frontal cortex & $0.35 \pm 0.11^{\#}$ & $0.45 \pm 0.10^{\#}$ & $0.22 \pm 0.07^{\#}$ & $0.78 \pm 0.14^{\# *}$ & $0.34 \pm 0.09^{\#}$ & $-0.06 \pm 0.02^{\# *}$ \\
\hline Visual cortex & $0.38 \pm 0.16$ & $0.34 \pm 0.05^{\#}$ & $0.04 \pm 0.06$ & $0.39 \pm 0.09^{\#}$ & $0.26 \pm 0.05^{\#}$ & $-0.0 \pm 0.06$ \\
\hline
\end{tabular}


Table 4

Pearson correlation coefficients between average acetylcholinesterase (AChE) intensity at the frontal cortex, averaged across both sides, with other histological and behaviora measures from 6 control and 9 lesion rats. High AChE intensity corresponds to a large number (Table 1). NBM, nucleus basalis magnocellularis; ChAT, choline acetyltransferase; LORR, loss of righting response. ${ }^{* *} \mathrm{P}<0.01,{ }^{*} \mathrm{P}<0.05$, Bonferroni adjusted probability.

\begin{tabular}{lc}
\hline $\begin{array}{l}\text { Correlation of average AChE intensity at frontal } \\
\text { cortex with }\end{array}$ & $\begin{array}{c}\text { Correlation } \\
\text { coefficient }\end{array}$ \\
\hline Number of ChAT immunopositive neurons in NBM $(\sim \mathrm{P} 1.4)$ & $0.78^{* *}$ \\
Average AChE intensity in the visual cortex & $0.94^{* *}$ \\
Propofol induced duration of loss of tail-pinch response & $-0.72^{*}$ \\
Propofol induced duration of LORR & $-0.83^{* *}$ \\
Pentobarbital induced duration of loss of tail-pinch response & -0.13 \\
Pentobarbital induced duration of LORR & -0.54 \\
Halothane induced infrared beam interrupts in first 5 min & -0.62 \\
Halothane induced duration of loss of tail-pinch response & -0.11 \\
Halothane induced duration of LORR & -0.25 \\
\hline
\end{tabular}

been previously reported (Wenk et al., 1994; Berntson et al., 2002; Kaur et al., 2008). In addition, Blanco-Centurion et al. (2006) reported that NBM lesion by 192IgG-saporin resulted in no change in sleep drive or the daily amounts of sleep-wake activities.

Neocortical low-voltage fast activity during quiet-awake was replaced by high-amplitude slow waves after infusion of muscimol

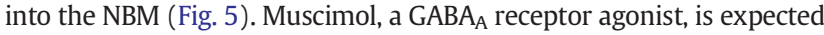
to hyperpolarize and inactivate both cholinergic and non-cholinergic neurons. Similar increase in high-amplitude slow waves in the neocortex during quiet-awake was found after permanent lesion of the NBM by kainic or ibotenic acid (Stewart et al., 1984; Buzsaki et al., 1988), which ablated both cholinergic and non-cholinergic neurons in the NBM (Kaur et al., 2008). Neocortical slow waves were also reported after administration of procaine into the NBM (Cape and Jones, 2000).

Despite the presence of neocortical slow-waves after muscimol infusion into the NBM, the rat was behaviorally awake and showed no signs of general anesthesia, i.e., its righting and pain responses were intact. This illustrates a dissociation of cortical slow-waves from sleep and general anesthesia. A dissociation of slow waves and sleep had been reported after atropine (Wikler, 1952; Vanderwolf, 1988) or muscimol injection into the pontine reticular formation (Flint et al., 2010), which suggests the fallacy of using EEG as the sole indicator of a behavioral state. On the other hand, large neocortical slow waves were typically associated with LORR induced by an anesthetic drug (Fig. 4B).

\section{Acetylcholine, NBM and general anesthesia}

One main original result reported here was that cholinotoxin lesion of the NBM prolonged the duration of LORR following several general anesthetics, including propofol $(5-10 \mathrm{mg} / \mathrm{kg}$ i.v.) and pentobarbital (20-40 mg/kg i.p.). In contrast, lesion of the NBM cholinergic neurons by 192IgG-saporin did not prolong the emergence from halothane anesthesia. The difference between anesthetic drugs may depend on their different molecular actions (Pittson et al., 2004; Franks, 2008) on various types of NBM neurons. In the present study, delayed emergence from halothane anesthesia was found after muscimol inactivation of the NBM, suggesting that inactivation of non-cholinergic NBM neurons may
A. Baseline
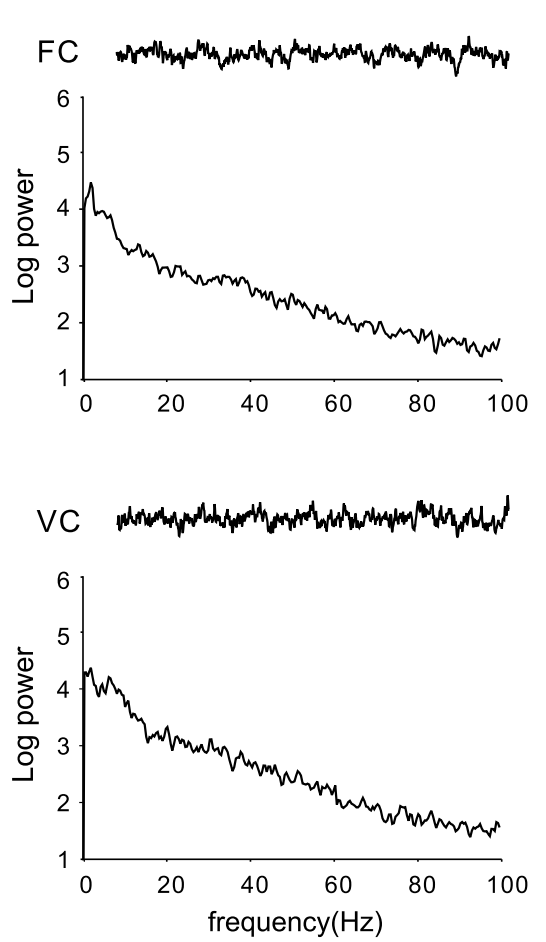

B. Muscimol
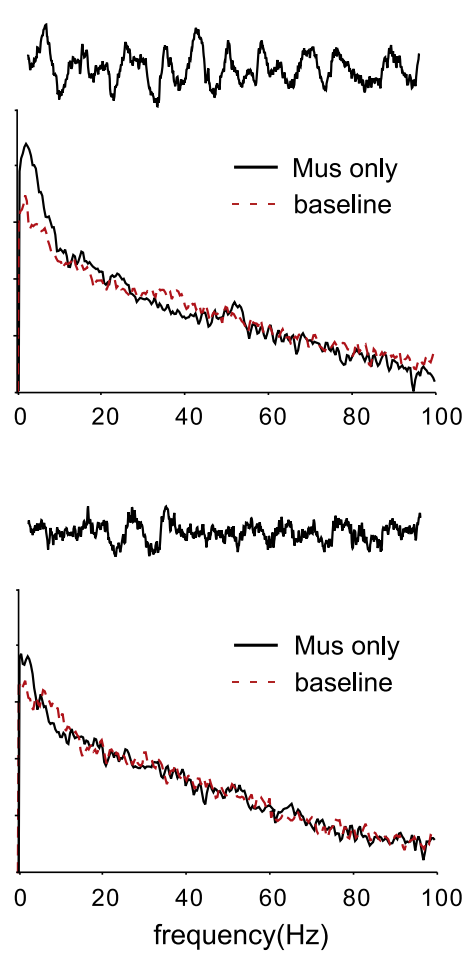

C. Mus + Propofol
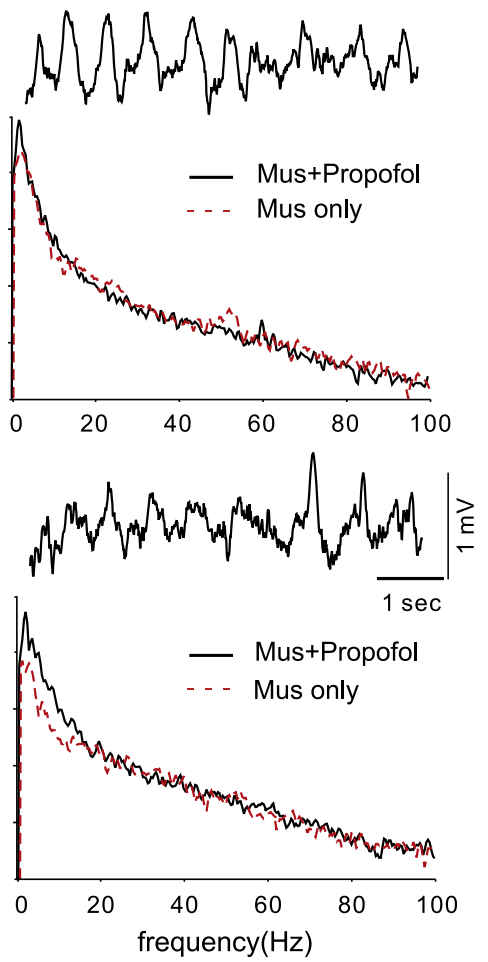

Fig. 5. Neocortical EEG slow waves during awake-immobility were enhanced after infusion of $G A B A_{A}$ receptor agonist, muscimol (Mus), into the nucleus basalis magnocellularis (NBM), and further by administration of propofol. EEG recorded in the frontal cortex (FC) and visual cortex (VC) before (A, baseline), and 10 min after bilateral infusion of muscimol $(0.4 \mu \mathrm{g}$ in $0.4 \mu \mathrm{l}$ saline) into the NBM (B, muscimol), and then $5 \mathrm{~min}$ after injection of $5 \mathrm{mg} / \mathrm{kg}$ i.v. propofol (C, Mus + propofol). The administration of propofol after NBM-muscimol infusion further enhanced slow waves in the FC and VC. 


\section{A. Propofol $5 \mathrm{mg} / \mathrm{kg}$ iv}

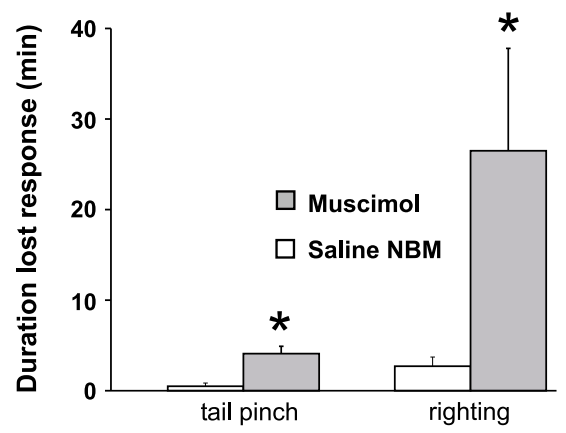

\section{Halothane (2\%)}

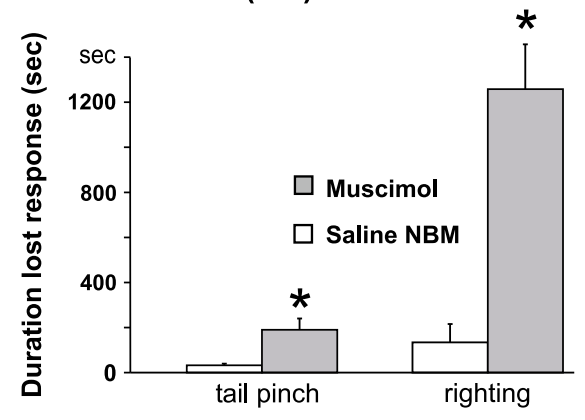

\section{B. Pentobarbital 20mg/kg ip}

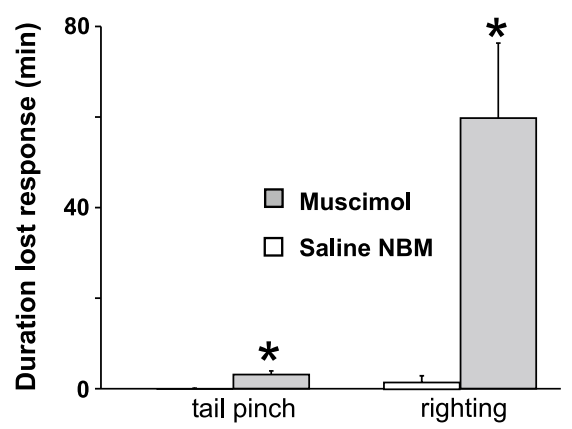

\section{Halothane (2\%)}

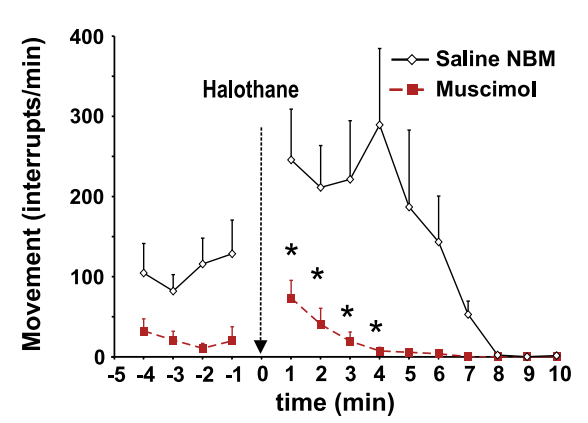

Fig. 6. Muscimol, as compared to saline, infusion in the nucleus basalis magnocellularis (NBM) prolonged the duration of lost response to tail-pinch and righting in rats after A) propofol $5 \mathrm{mg} / \mathrm{kg}$ i.v., B) sodium pentobarbital ( $20 \mathrm{mg} / \mathrm{kg}$ i.p.), and C) halothane (2\%). D) The number of infrared beam interruptions (horizontal movements) induced by halothane (2\%) was smaller in rats pre-treated with muscimol as compared to saline in the NBM ( ${ }^{*} \mathrm{P}<0.05$, Wilcoxon test for fist $4 \mathrm{~min}$ after halothane). Muscimol $(0.4 \mu \mathrm{g}$ in $0.4 \mu \mathrm{l}$ saline), or $0.4 \mu \mathrm{l}$ saline, was infused bilaterally into the NBM 10 min before administration of an anesthetic drug. ${ }^{*} \mathrm{P}<0.05$, paired Wilcoxon, difference between saline and muscimol-infused groups. Six rats were used in each experiment (B, C and D) except 10 rats were given propofol (A).

be required for delayed emergence from halothane anesthesia. Preliminary data also showed that kainic acid infusion into the NBM depleted both ChAT- and PARV-immunopositive neurons and prolonged the emergence from halothane anesthesia (Leung and Petropoulos, unpublished data).

Stage II anesthesia induced by a volatile anesthetic is characterized by delirium or behavioral excitation (Guedel, 1951). We showed that the delirium induced by halothane was reduced by cholinergic lesion or muscimol-inactivation of the NBM. However, delirium but not emergence time was affected by NBM cholinergic lesion, suggesting that the mechanisms underlying delirium and anesthesia emergence are different. Muscimol-inactivation of the medial septum, hippocampus and connected limbic areas (Ma et al., 2002; Ma and Leung, 2006; Long et al., 2009) were shown to reduce delirium and increase emergence time from halothane anesthesia.

This study provides original evidence that cholinergic neurons in the NBM are important in the behavioral responses to general anesthetics. The results are generally consistent with previous studies. Increasing central Ach levels is known to reduce the depth of anesthesia (Meuret et al., 2000; Hudetz et al., 2003). Laalou et al. (2008) reported that NBM lesion with 192IgG-saporin increased the anesthetic, but not the subanesthetic, effects of cumulative doses of propofol (i.p.). We showed that $5 \mathrm{mg} / \mathrm{kg}$ i.v. propofol resulted in surgical anesthesia (loss of both tail-pinch and righting responses) in all NBM 192IgG-saporin lesioned rats but not in any of the control rats. Thus, injection through the usual route of administration of propofol (i.v.) potentiated the effect of a subanesthetic dose.

The participation of the NBM in general anesthetic responses likely involves the projection of NBM to the thalamus and neocortex, but downstream projections from the NBM to the hypothalamus and brainstem (Semba, 2000) may also be involved. NBM projects to arousal promoting neurons in the hypothalamus (containing histamine or orexin), locus coeruleus, raphe, and mesencephalic locomotor region (MLR; Mogenson et al., 1993), mainly through GABAergic connections (Semba, 2000). A nucleus accumbens-subpallidum (NBM)-MLR pathway (Mogenson et al., 1993) is a possible route that the limbic system modulates the effects of general anesthesia (Ma et al., 2002; Ma and Leung, 2006). MLR inactivation has been shown to decrease the minimum alveolar concentration of isoflurane in rats (Jinks et al., 2010).

Lesion or inactivation of various brain structures other than NBM was shown to prolong the duration of LORR induced by general anesthetics. Inactivation of the medial septum, hippocampus, nucleus accumbens, ventral pallidum, ventral tegmental area and supramammillary area prolonged the LORR induced by both pentobarbital and halothane (Ma et al., 2002; Ma and Leung, 2006), while inactivation of the entorhinal cortex and piriform cortex mainly prolonged the LORR induced by pentobarbital but not halothane (Long et al., 2009). Infusion of muscimol into the mesopontine tegmentum (Devor and Zalkind, 2001) or tuberomammillary nucleus (Nelson et al., 2002) may induce LORR. Like the NBM, inactivation of a brain structure may enhance general anesthetic responses by influencing sleep-wake circuits. Whether several structures, when inactivated, may affect one or several sleep-wake circuits remain to be studied.

This study demonstrates that a loss of cholinergic basal forebrain neurons increases the time of emergence for some general anesthetics. Whether this applies to general anesthesia in aged humans and Alzheimer's patients (Fodale et al., 2006) remains to be investigated. 
Aging is associated with $30-50 \%$ decline in number of cholinergic neurons in the NBM of rats (Smith and Booze, 1995) and humans (de Lacalle et al., 1991; Guela and Mesulam, 1994).

\section{Acknowledgments}

The authors thank J. Yang for technical assistance. Supported by a Canadian Institutes of Health Research operating grant MOP-15685.

\section{References}

Auld, D.S., Kornecook, T.J., Bastianetto, S., Quirion, R., 2002. Alzheimer's disease and the basal forebrain cholinergic system: relations to beta-amyloid peptides, cognition, and treatment strategies. Prog. Neurobiol. 68, 209-245.

Bartus, R.T., 2000. On neurodegenerative diseases, models, and treatment strategies: lessons learned and lessons forgotten a generation following the cholinergic hypothesis. Exp. Neurol. 163, 495-529.

Berntson, G.G., Shafi, R., Sarter, M., 2002. Specific contributions of the basal forebrain corticopetal cholinergic system to electroencephalographic activity and sleep/ waking behaviour. Eur. J. Neurosci. 16, 2453-2461.

Bigl, V., Woolf, N.J., Butcher, L.L., 1982. Cholinergic projections from the basal forebrain to frontal, parietal, temporal, occipital and cingulated cortices: a combined fluorescent tracer and acetylcholinesterase analysis. Brain Res. Bull. 8, 727-749.

Blanco-Centurion, C., Xu, M., Murillo-Rodriguez, E., Gerashchenko, D., Shiromani, A.M. Salin-Pascual, R.J., Hof, P.R., Shiromani, P.J., 2006. Adenosine and sleep homeostasis in the basal forebrain. J. Neurosci. 26, 8092-8100.

Buzsaki, G., Bickford, R.G., Ponomareff, G., Thal, L.J., Mandel, R., Gage, F.H., 1988. Nucleus basalis and thalamic control of neocortical activity in the freely moving rat. J. Neurosci. 8, 4007-4026.

Cape, E.G., Jones, B.E., 2000. Effects of glutamate agonist versus procaine microinjections into the basal forebrain cholinergic cell area upon gamma and theta EEC activity and sleep-wake state. Eur. J. Neurosci. 12, 2166-2184.

de Lacalle, S., Iraizoz, I., Gonzalo, L.M., 1991. Differential changes in cell size and number in topographic subdivisions of human basal nucleus in normal aging. Neuroscience $43,445-456$.

Detari, L., Rasmusson, D.D., Semba, K., 1999. The role of basal forebrain neurons in tonic and phasic activation of the cerebral cortex. Prog. Neurobiol. 58, 249-277.

Devor, M., Zalkind, V., 2001. Reversible analgesia, atonia, and loss of consciousness on bilateral intracerebral microinjection of pentobarbital. Pain 94, 101-112.

Dringenberg, H.C., Olmstead, M.C., 2003. Integrated contributions of basal forebrain and thalamus to neocortical activation elicited by pedunculopontine tegmental stimulation in urethane-anesthetized rats. Neuroscience 119, 839-853.

Everitt, B.J., Robbins, T.W., 1997. Central cholinergic systems and cognition. Annu. Rev. Psychol. 48, 649-684.

Flint, R.R., Chang, T., Lydic, R., Baghdoyan, H.A., 2010. GABA(A) receptors in the pontine reticular formation of $\mathrm{C} 57 \mathrm{BL} / 6 \mathrm{~J}$ mouse modulate neurochemical, electrographic, and behavioral phenotypes of wakefulness. J. Neurosci. 30, 12301-12309.

Fodale, V., Quattrone, D., Trecroci, C., Caminiti, V., Santamaria, L.B., 2006. Alzheimer's disease and anaesthesia: implications for the central cholinergic system. Br. J. Anaesth. 97 (4), 445-452.

Franks, N.P., 2008. General anaesthesia: from molecular targets to neuronal pathways of sleep and arousal. Nat. Rev. Neurosci. 9, 370-386.

Gritti, I., Mainville, L., Mancia, M., Jones, B.E., 1997. GABAergic and other noncholinergic basal forebrain neurons project together with cholinergic neurons to meso- and iso-cortex in the rat. J. Comp. Neurol. 383, 163-177.

Guedel, A.E., 1951. Inhalation Anesthesia: A Fundamental Guide, 2nd ed. Macmillan, New York.

Guela, C., Mesulam, M.M., 1994. Cholinergic system and related neuropathological predilection patterns in Alzheimer disease. In: Terry, R.D., Katzman, R., Bick, K.L. (Eds.), Alzheimer Disease. New York, Raven Press.

Hassani, O.K., Lee, M.G., Henny, P., Jones, B.E., 2009. Discharge profiles of identified GABAergic in comparison to cholinergic and putative glutamatergic basal forebrain neurons across the sleep-wake cycle. J. Neurosci. 29, 11828-11840.

Heckers, S., Ohtake, T., Wiley, R.G., Lappi, D.A., Geula, C., Mesulam, M.-M., 1994 Complete and selective cholinergic denervation of rat neocortex and hippocampus but not amygdala by an immunotoxin against the p75 NGF receptor. J. Neurosci. 14, 1271-1289.

Hudetz, A.G., Wood, J.D., Kampine, J.P., 2003. Cholinergic reversal of isoflurane anesthesia in rats as measured by cross-approximate entropy of the electroencephalogram. Anesthesiology 99, 1125-1131.

Jinks, S.L., Bravo, M., Satter, O., Chan, Y.M., 2010. Brainstem regions affecting minimum alveolar concentration and movement pattern during isoflurane anesthesia. Anesthesiology 112 (2), 316-324.

Jones, B.E., 2004. Activity, modulation and role of basal forebrain cholinergic neurons innervating the cerebral cortex. Prog. Brain Res. 145, 157-169.

Kaur, S., Junek, A., Black, M.A., Semba, K., 2008. Effects of ibotenate and 192IgG-saporin lesions of the nucleus basalis magnocellularis/substantia innominata on spontaneous sleep and wake states and on recovery sleep after sleep deprivation in rats. J. Neurosci. 28, 491-504.

Kelz, M.B., Sun, Y., Chen, J., Cheng, M.Q., Moore, J.T., Veasey, S.C., Dixon, S., Thornton, M., Funato, H., Yanagisawa, M., 2008. An essential role for orexins in emergence from general anesthesia. Proc. Natl Acad. Sci. USA 105, 1309-1314.
Koelle, G.B., Friedenwald, J.S., 1949. A histochemical method for localizing cholinesterase activity. Proc. Soc. Exp. Biol. 70, 617-622

Laalou, F.Z., de Vasconcelos, A.P., Oberling, P., Jeltsch, H., Cassel, J.C., Pain, L., 2008. Involvement of the basal cholinergic forebrain in the mediation of general (propofol) anesthesia. Anesthesiology 108 (5), 888-896.

Lee, M.G., Hassani, O.K., Alonso, A., Jones, B.E., 2005. Cholinergic basal forebrain neurons burst with theta during waking and paradoxical sleep. J. Neurosci. 25 , 4365-4369.

Leung, L.S., 1985. Spectral analysis of hippocampal EEG in the freely moving rat: effects of centrally active drugs and relations to evoked potentials. Electroencephalogr. Clin. Neurophysiol. 60, 65-77.

Leung, L.S., 1987. Hippocampal electrical activity following local tetanization. I. Afterdischarges. Brain Res. 419, 173-187.

Long, J.L., Shen, B., Luo, T., Stewart, L., McMurran, T.J.A., Leung, L.S., 2009. Pilocarpine model of temporal lobe epilepsy shows enhanced response to general anesthetics. Exp. Neurol. 219, 308-318.

Lu, J., Nelson, L.E., Franks, N., Maze, M., Chamberlin, N.L., Saper, C.B., 2008. Role of endogenous sleep-wake and analgesic systems in anesthesia. J. Comp. Neurol. 508 (4), 648-662.

Luo, T., Leung, L.S., 2009. Basal forebrain histaminergic transmission modulates electroencephalographic activity and emergence from isoflurane anesthesia. Anesthesiology $111,725-733$.

Ma, J., Leung, L.S., 2006. Limbic system participates in mediating the effects of general anesthetics. Neuropsychopharmacology 31, 1177-1192.

Ma, J., Shen, B., Stewart, L.S., Herrick, I.A., Leung, L.S., 2002. The septohippocampal system participates in general anesthesia. J. Neurosci. 22 (RC200), 1-6.

Ma, J., Shen, B., Rajakumar, N., Leung, L.S., 2004. The medial septum mediates impairment of prepulse inhibition of acoustic startle induced by a hippocampal seizure or phencyclidine. Behav. Brain Res. 155, 153-166.

Manns, I.D., Alonso, A., Jones, B.E., 2003. Rhythmically discharging basal forebrain units comprise cholinergic, GABAergic, and putative glutamatergic cells. J. Neurophysiol. 89, 1057-1066.

Mckinney, M., Coyle, J.T., Hedreen, J.C., 1983. Topographic analysis of the innervation of the rat neocortex and hippocampus by the basal forebrain cholinergic system. J. Comp. Neurol. 217, 103-121.

Mesulam, M.M., Mufson, E.J., Wainer, B.H., Levey, A.I., 1983. Central cholinergic pathways in the rat: an overview based on an alternative nomenclature (Ch1-Ch6). Neuroscience 10, 1185-1201.

Meuret, P., Backman, S.B., Bonhomme, V., Plourde, G., Fiset, P., 2000. Physostigmine reverses propofol-induced unconsciousness and attenuation of the auditory steady state response and bispectral index in human volunteers. Anesthesiology 93,708-717.

Mogenson, G.J., Brudzynski, S.M., Wu, M., Yang, C.R., Yim, C.Y., 1993. From motivation to action: a review of dopaminergic regulation of limbic-nucleus accumbens-ventral pallidum-pedunculopontine nucleus circuits involved in limbic-motor integration. In: Kalivas, P.W., Barnes, C.D. (Eds.), Limbic Motor Circuits and Neuropsychiatry. CRC Press, Boca Raton, FL, pp. 193-225.

Nelson, L.E., Guo, T.Z., Lu, J., Saper, C.B., Franks, N.P., Maze, M., 2002. The sedative component of anesthesia is mediated by GABAA receptors in an endogenous sleep pathway. Nat. Neurosci. 5, 979-984.

Pain, L., Jeltsch, H., Lehmann, O., Lazarus, C., Laalou, F.Z., Cassel, J.C., 2000. Central cholinergic depletion induced by $192 \mathrm{IgG}$-saporin alleviates the sedative effects of propofol in rats. Br. J. Anaesth. 85, 869-873.

Paxinos, G., Watson, C., 1998. The Rat Brain in Stereotaxic Coordinates, 4th ed. Academic Press, New York.

Paxinos, G., Watson, C., 2009. The Rat Brain in Stereotaxic Coordinates. compact 6th ed. Academic Press, New York

Perry, E., Walker, M., Grace, J., Perry, R., 1999. Acetylcholine in mind: a neurotransmitter correlate of consciousness? Trends Neurosci. 22, 273-280.

Phyllis, J.W., 2005. Acetylcholine release from the central nervous system: a 50-year retrospective. Crit. Rev. Neurobiol. 17 (3-4), 161-217.

Pittson, S., Himmel, A.M., MacIver, M.B., 2004. Multiple synaptic and membrane sites of anesthetic action in the CA1 region of rat hippocampal slices. BMC Neurosci. 5, 52.

Saper, C.B., 1984. Organization of cerebral cortical afferent systems in the rat. I. Magnocellular basal nucleus. J. Comp. Neurol. 222, 313-342.

Sarter, M., Hasselmo, M.E., Bruno, J.P., Givens, B., 2005. Unraveling the attentional functions of cortical cholinergic inputs: interactions between signal-driven and cognitive modulation of signal detection. Brain Res. Rev. 48, 98-111.

Semba, K., 2000. Multiple output pathways of the basal forebrain: organization, chemical heterogeneity, and roles in vigilance. Behav. Brain Res. 115, 117-141.

Smith, M.L., Booze, R.M., 1995. Cholinergic and GABAergic neurons in the nucleus basalis region of young and aged rats. Neuroscience 67, 679-688.

Steriade, M., 2000. Corticothalamic resonance, states of vigilance and mentation. Neuroscience 101, 243-276.

Stewart, D.J., MacFabe, D.F., Vanderwolf, C.H., 1984. Cholinergic activation of the electrocorticogram: role of substantia innominata and effects of atropine and quinuclidinyl benzilate. Brain Res. 322, 219-232.

Szymusiak, R., Alam, N., McGinty, D., 2000. Discharge patterns of neurons in cholinergic regions of the basal forebrain during waking and sleep. Behav. Brain Res. 115, 171-182.

Tung, A., Szafran, M.J., Bluhm, B., Mendelson, W.B., 2002. Sleep deprivation potentiates the onset and duration of loss of righting reflex induced by propofol and isoflurane. Anesthesiology 97, 906-911.

Vanderwolf, C.H., 1988. Cerebral activity and behavior: control by central cholinergic and serotonergic systems. Int. Rev. Neurobiol. 30, 225-340.

Vazquez, J., Baghdoyan, H.A., 2001. Basal forebrain acetylcholine release during REM sleep is significantly greater than during waking. Am. J. Physiol. Regul. Integr. Comp. Physiol. 280, R598-R601. 
Wenk, G.L., 1997. The nucleus basalis magnocellularis cholinergic system: one hundred years of progress. Neurobiol. Learn. Mem. 67, 85-95.

Wenk, G.L., Stoehr, J.D., Quintana, G., Mobley, S., Wiley, R.G., 1994. Behavioral, biochemical, histological, and electrophysiological effects of 192 IgGsaporin injections into the basal forebrain of rats. J. Neurosci. 14, 5986-5995.
Whitehouse, P., Price, D., Struble, R., Clark, A., Coyle, J., Delong, M., 1981. Alzheimer's disease and senile dementia: loss of neurons in the basal forebrain. Science 215, 1237-1239.

Wikler, A., 1952. Pharmacologic dissociation of behavior and EEG "sleep patterns" in dogs: morphine, N-allylnormorphine, and atropine. Proc. Soc. Exp. Biol. Med. 79, 261-265. 